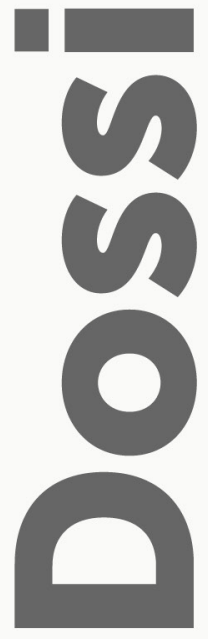

\title{
Um lugar para o corpo: fotografias familiares em contexto de luto
}

\author{
A place for the body: \\ family photographs in a context of grief

\section{RESUMO}

Desde o seu surgimento, em 1839, o dispositivo fotográfico foi amplamente utilizado para retratar a família, seus membros e vínculos. A nova imagem técnica logo se tornou parte essencial da vida doméstica, exibindo o meio familiar como instituição social e como portador de laços íntimos e amorosos. O artigo aborda o universo da fotografia de família, destacando sua produção e seu uso no contexto funerário e de luto. A ideia central é a de que o retrato fotográfico, depois da morte da pessoa retratada, torna-se o novo corpo do morto, lugar de contato e vínculo. O luto é pensado como um estado permanente de conexão do vivo com os seus mortos. Olhar a fotografia do ausente é uma forma do vivo ser olhado de volta, um meio dele também não ser esquecido. A presença de ambos os corpos, o do vivo e o do morto, é essencial no processo simbólico que se desenrola, que faz projetar uma relação sempre atualizada. Mas, por fim, talvez sejam as fotografias objetos puramente melancólicos e vazios, através dos quais se evidencia a solidão dos sobreviventes.

Palavras-chave: Fotografia - Luto - Morte - Memória - Presença

\begin{abstract}
Since its emergence in 1839, photographic devices have been largely employed to depict the family, its members and their connections. The new technical image soon became an essential part of domestic life, exhibiting the familial environment both as a social institution and as the carrier of intimate and amorous bonds. The article approaches the universe of family photography with an emphasis on its production and use in funerary and grief contexts. The central idea is that the photographic portrait becomes the new body of the depicted person after his/her death, a place of contact and bond. Grief is understood as a permanent state of connection between the living and their dead. Looking at the photograph of the absent is a means for the living to be looked at in return, and also of not being forgotten. The presence of both bodies, the living and the dead, is essential to the symbolic process that unfolds and projects a constantly renewed relationship. Photographs are, perhaps, purely melancholic and empty objects, through which the loneliness of those who survived is made evident.
\end{abstract}

Keywords: Photography - Mourning - Death - Memory - Presence

* Pós-doutoranda no Departamento de Antropologia da Universidade de São Paulo (USP/FAPESP). Doutora em Artes pela Escola de Belas Artes da Universidade Federal de Minas Gerais (UFMG), com estágio sanduíche na Faculté des Sciences Sociales/Université de Strasbourg. Pesquisadora do GRAVI - Grupo de Antropologia Visual, da Universidade de São Paulo (USP). CV: http://lattes.cnpq.br/4424795994290721 
A foto é literalmente uma emanação do referente. De um corpo real, que estava lá, partiram radiações que vêm me atingir, a mim, que estou aqui; pouco importa a duração da transmissão; a foto do ser desaparecido vem me tocar como os raios retardados de uma estrela. (Barthes, 1984, p. 121)

O trabalho de luto consiste menos em afastaro morto (matá-lo definitivamente; um indivíduo só está morto quando é completamente esquecido) do que em tentar fazê-lo (sobre)viver em imagem. (Thomas, 1985, p. 511). ${ }^{1}$

\section{Prólogo}

Nos primeiros dias do ano de 2013 decidi fazer uma longa viagem. Nela, vi imagens, monumentos, cemitérios, caminhei por lugares que me afetaram profundamente. Eu compreendi, ali, que a produção de imagens ao longo dos tempos teve vigorosamente um sentido funerário e que a imagem da morte - ainda que não mostrasse o rosto do morto - foi a que rondou toda a história do homem. Depois, comecei o caminho de volta. Faltavam sete dias para chegar em casa quando o meu avô morreu no Brasil. Eu estava em Portugal, terra em que ele nascera. Pedi então ao meu irmão que o fotografasse. Naquele dia eu vi, pela primeira vez, a verdadeira fotografia de um morto. Não era mais um objeto de estudo, uma imagem longínqua, protegida por seu anonimato. Era o meu avô, seu corpo exposto, imóvel, cadáver mais uma vez imobilizado pela fotografia. Mal poderia saber, antes, que a viagem de pesquisa, muito mais do que ver monumentos, cemitérios e museus, seria o acolhimento da morte do meu avô em imagem. Não o vi. Seu corpo e seu rosto eram de um outro. Mas era, ainda, o meu avô, desviado, redesenhado pela morte.

De volta, eu tentava recompor os seus últimos dias através de outras fotografias. Em casa, antes de ser levado ao hospital; internado, porém ainda consciente; já inconsciente; os últimos instantes. Essas fotografias tentavam me desvencilhar da perturbação de voltar para casa e encontrar uma pequena urna de cerâmica no lugar do corpo do meu avô. Três meses depois retornei a Portugal, levando a caixa com as cinzas. Para além de razões religiosas, o objetivo era dar-lhe nome e visibilidade no lugar onde nascera, afrontar o esquecimento a que se sujeita todo homem morto, fazendo-lhe um monumento. Escolhi então a primeira fotografia que ele tirou no Brasil, a do jovem homem que deixara o seu país. É esta imagem que agora retorna à casa e estampa a pedra que o guarda, sobre o seu nome impresso. Dentro da caixinha guardei diversas fotografias, junto aos restos de seu corpo. Eu tentara lhe mostrar essas fotos enquanto estava vivo, já doente, mas senti a recusa do seu olhar na desculpa de não as enxergar bem. Ele não quis vê-las, compreendi como gesto insuportável olhar imagens do passado quando se está tão perto da morte. Mas, agora, estando já morto, eu contava-lhe a única história, incerta e desordenada, que eu poderia ainda contar, da vida que correu, das imagens que restaram e do afeto, isso que faz recolher os restos de um homem, para que ele não seja esquecido.

1 “Le travail du deuil consiste moins à mettre à l'écart le mort (le tuer définitivement; un sujet n'est mort que s'il est complètement oublié) qu'à tenter de le faire (sur)vivre en image". Tradução nossa. 
I.

Antonino Paraggi, personagem de Italo Calvino, de profissão administrativa e pensamentos filosóficos, parte de um curioso pressuposto em sua aventura de tornar-se um fotógrafo: se é preciso fotografar, que se fotografe tudo (Calvino, 1992). Antes, quando rejeitava de maneira veemente a ideia de fotografar, vendo seus amigos coletarem incansáveis imagens de suas crianças, da alegria domingueira e fugaz, de momentos específicos que nada diziam dos outros, anteriores e seguintes a eles, Antonino sentia-se cada vez mais solitário na sua "recusa em viver o presente como lembrança futura". Mas, diante de seus amigos, e exercendo uma profunda reflexão sobre o assunto, Antonino chegara à conclusão de que, se uma pessoa quer apreender os instantes, "o único modo de agir com coerência é tirar pelo menos uma foto por minuto desde quando abre os olhos de manhã até quando vai dormir". Sua concepção do verdadeiro ato fotográfico vai mais longe:

Só assim os rolos de filme constituirão um diário fiel de nossas jornadas, sem que nada fique excluído. Se eu fosse me meter a fotografar, iria até o fim nesse caminho, à custa de perder a razão com isso. Já vocês ainda pretendem estar fazendo uma escolha. Mas qual? Uma escolha no sentido idílico, apologético, de consolação, de paz com a natureza, a nação, os parentes. Não é apenas uma escolha fotográfica, a de vocês; é uma escolha de vida, que os leva a excluir os contrastes dramáticos, os cernes das contradições, as grandes tensões da vontade, da paixão, da aversão (Calvino, 1992, p. 55).

Antonino propõe, então, não um álbum constituído por uma seleção de instantes, momentos fotografáveis para compor o imaginário familiar. Imaginário que se dá não em sua totalidade, mas na ficção das pequenas escolhas, o que torna o álbum familiar sempre uma espécie de teatro dos melhores momentos. Portanto, não se trata de fotografar somente alguns instantes, insiste Antonino, mas todos eles:

- ...Porque uma vez que você começou - perorava, não há nenhuma razão para parar. O passo entre a realidade que é fotografada na medida em que nos parece bonita e a realidade que nos parece bonita na medida em que foi fotografada é curtíssimo. Se você fotografa Pierluca enquanto ele está fazendo o castelo de areia, não há razão para não fotografá-lo enquanto está chorando porque o castelo desmoronou, e depois enquanto a ama o consola fazendo-o encontrar no meio da areia uma casquinha de concha. É só você começar a dizer a respeito de alguma coisa: "Ah, que bonito, tinha era que tirar uma foto!", e já está no terreno de quem pensa que tudo o que não é fotografado é perdido, que é como se não tivesse existido, e que então para viver de verdade é preciso fotografar o mais que se possa, e para fotografar o mais que se possa é preciso ou viver de um modo o mais fotografável possivel, ou então considerar fotografáveis todos os momentos da própria vida. (Calvino, 1992, p. 54). 
A fotografia, então, enlouquece Antonino. Se, no começo, ele tentara fazer imagens solenes tal como no século XIX, ao notar a incapacidade da fotografia de responder ao seu anseio da verdade em uma única imagem - uma imagem que seria "o retrato fora do tempo e do espaço" -, nosso herói é levado ao desespero da imagem-pós-imagem, numa sucessão infinita de futuros e passados, de um presente continuamente desaparecido nas tramas do ato fotográfico. Apaixonado por uma mulher (o gesto desenfreado do fotógrafo nascera junto com o amor), Antonino não consegue parar de fotografá-la, dia e noite, acordada ou a dormir, com um enorme dispositivo construído para não perder nada. Ao ser questionado pelos amigos, ele respondia que era uma questão de método: "Qualquer pessoa que você resolva fotografar, ou qualquer coisa, você tem que continuar a fotografá-la sempre, só ela, a todas as horas do dia e da noite. A fotografia só tem sentido se esgotar todas as imagens possíveis" (Calvino, 1992, p. 62). Depois, quando a mulher enfim o deixara, ele fotografava, compulsivamente, a ausência dela. E, quando esgotara toda a ausência, nos cantos e objetos da casa, ele despedaçou todas as fotografias, para, ao final, fotografar as fotografias despedaçadas.

A aventura de Antonino coloca-nos diante da questão: por que fazer imagens? Por que transformar o presente numa lembrança futura, lidando com os três tempos de forma tão imprecisa? Mas, ainda mais pontualmente: o que rege nossas escolhas para fotografar o ser amado? Do cotidiano partilhado aos grandes ritos de passagem, por onde passa o desejo de não perder, de não o perder? Quando surge a fotografia, em 1839, logo surgem os retratos amorosos e familiares. Solenes, montados, teatralizados. Havia um tempo da fotografia que era outro, a pose exigia uma postura rígida, firme; exigia, portanto, um olhar fixo e uma imobilidade como a da morte. Ela, a morte, desapareceu aos poucos dos nossos álbuns. É um rito que, em geral, não faz mais parte do nosso acervo de imagens (não suportamos o seu rosto ou dela não queremos nos lembrar?). Mas, por muito tempo, a morte foi um dos assuntos centrais da fotografia. Duas imobilidades se colocavam diante do olhar. Era uma época em que a morte podia ser olhada e, portanto, fotografada. A passagem do tempo, de lá para cá, muito nos ensina sobre o nosso olhar, quando notamos que já não podemos mirar, com aqueles mesmos olhos, o rosto da morte. Mas, afinal, não seria folhear um antigo álbum familiar um olhar lançado aos mortos? O que jaz nesses álbuns, ou nas caixas e gavetas onde se guardam as velhas fotografias?

É preciso deixar claro que o pensamento sobre o álbum fotográfico, aqui, constituise de um pensamento ampliado desse álbum e mesmo das imagens de memória, de família, de afeto. Seja o antigo álbum de papel cartão, com suas entrefolhas de papel manteiga e suas cantoneiras, ou as folhas adesivas transparentes, ou pequenos álbuns com folhas de plástico de lojas de revelação, com suas belas fotografias analógicas, por vezes já desbotadas, ou ainda os nossos contemporâneos álbuns virtuais, trata-se, antes de tudo, de pensar a fotografia feita e partilhada no meio familiar, social e afetivo. Certamente, tudo mudou dos primórdios do álbum fotográfico do século XIX para agora. Os meios digitais e as redes sociais ampliaram a noção de "família", de "meio social" e mesmo de "afeto", para relações diversas e muitas vezes ficcionais, 
o que não difere, em muitos casos, dos vínculos familiares habituais. ${ }^{2}$ Mas restam as imagens, essas instâncias partilhadas com o próximo e o distante, elas que muitas vezes nos dão um lugar, que nos dão origem e nome, que nos dão um rosto. Aqui, o pensamento partirá das fotografias familiares e amorosas, para ir em direção à experiência do luto através da imagem.

II.

Walter Benjamin, em seu célebre ensaio "A obra de arte na era de sua reprodutibilidade técnica", exaltou a chegada da fotografia como o advento da arte em massa e para as massas. Para ele, a partir da fotografia e do seu poder de reprodução, o desejo do homem de possuir imagens seria satisfeito. Através da reprodução técnica, a imagem perdia seu caráter único, o que a emancipava também de um valor de culto. Segundo Benjamin, uma das perdas centrais dessa nova imagem dizia respeito ao que ele chamou de aura, "a aparição única de uma coisa distante, por mais perto que ela esteja" (Benjamin, 1994, p. 170). A aura, tal como pensada pelo autor, existiria nas obras únicas e autênticas, no original. Ele associa essa ideia a uma unicidade espaço-temporal da experiência. A teoria de Benjamin é que a imagem técnica destrói a aura ao ser multiplicada, e é com satisfação que ele constata isso, já que a aura era também o que conservava a arte longe do uso cotidiano, comum, das massas. Com a destruição da aura, as coisas ficariam mais próximas e, segundo o teórico, a tendência das massas modernas era a de "superar o caráter único de todos os fatos através de sua reprodutibilidade" (Benjamin, 1994, p. 170).

Benjamin fala também sobre uma crise na percepção: "No interior de grandes períodos históricos, a forma de percepção das coletividades humanas se transforma ao mesmo tempo que seu modo de existência" (Benjamin, 1994, p. 169). A fotografia, inevitavelmente, precisou criar um novo público, ou, ao menos, novos olhos para lidar com ela. Até então o mundo havia visto somente imagens construídas pelo homem, pelas mãos do homem. Pela primeira vez, acreditava-se que havia uma máquina criando imagens, elas que jamais haviam chegado tão perto do real, da ideia de uma documentação efetiva da realidade. Dentro desse novo público, havia gente deslumbrada e gente aterrorizada - mas todos queriam ser fotografados. Independentemente da relação que cada pessoa travou com a nova imagem técnica, uma coisa era certa: algo havia mudado definitivamente no olhar daquele século.

Outra novidade que a fotografia trouxe foi a experiência de olhar o próprio rosto via imagem. Roland Barthes, quase 150 anos depois do advento da fotografia, disse sentir sua própria transformação em imagem como uma micro experiência da morte: "tornome verdadeiramente espectro" (Barthes, 1984, p. 27). O semiólogo francês escreveu apaixonadamente sobre fotografia, e o livro foi o seu trabalho de luto após a perda da mãe. Na

\footnotetext{
2 A concepção da ideia de família é complexa e problemática. Essa palavra pode ter um significado pleno de afeto como ser somente parte de um estatuto social. É difícil - na maioria dos casos - delimitar a atuação da palavra família. Portanto, aqui, ela estará solta, entre afeto e instituição, vagando entre os dois como vaga, de fato, na constituição de suas relações.
} 
morte, ele voltou-se para as imagens fotográficas e tentou aprender algo sobre a perda com elas. Talvez por viver o luto no instante da escrita, talvez porque a fotografia seja mesmo indissociável da morte, seus estudos são os que mais aproximam a imagem e a perda, a ferida, o morto e o vivo, que coabitam o mesmo espaço fixado em sais de prata. O fato é que há algo de terrível na nossa própria imagem congelada; ela é a visão, senão da Morte, de uma morte possível. Talvez aqueles homens do século XIX não estivessem perto de sentir algo semelhante, mas creio haver na fotografia, desde os seus primórdios, esse gosto pelo que não vive mais, o gosto pelo tempo congelado e para sempre perdido. Isso já estava lá, desde o começo, mesmo que não elaborado, não percebido.

Benjamin também falaria sobre a ideia do valor de culto que, segundo ele, ainda restava nos retratos fotográficos, apesar da reprodutibilidade a que estavam sujeitos. O rosto humano seria o lugar de resistência da aura, com sua inexorável promessa de trazer de volta algo do desaparecido. A saudade, alimentada pelo rosto amoroso da imagem, tornara-se então o valor moderno de culto.

Mas o valor de culto não se entrega sem oferecer resistência. Sua última trincheira é o rosto humano. Não é por acaso que o retrato era o principal tema das primeiras fotografias. O refúgio derradeiro do valor de culto foi o culto da saudade, consagrada aos amores ausentes ou defuntos. A aura acena pela última vez na expressão fugaz de um rosto, nas antigas fotos. É o que lhes dá sua beleza melancólica e incomparável (Benjamin, 1994, p. 174).

A aura acenava pela última vez e surgia, com a fotografia, um novo meio de produção de memória, de concepção icônica e de adoração de imagens. Se a aura ainda acena nos retratos familiares, isso diz respeito ao seu valor afetivo, associado a um valor de culto. Mas também diz respeito ao seu valor de real, do "ter acontecido", o que Barthes (1984, p. 115) chamou de o "isso foi" da fotografia. Quando olhamos nossos antigos álbuns, as antigas fotos familiares em que geralmente há menos vivos do que mortos, mais do que pessoas, nós vemos o tempo passado, e sabemos que, um dia, aquilo aconteceu. O olhar que lançamos hoje para aquele tempo congelado reaviva algo do mundo dos mortos: "é a imagem viva de uma coisa morta" (Barthes, 1984, p. 118). Talvez a aura esteja em torno desse lugar impossivel, de tornar carne e osso o que não existe mais.

Os retratos tornar-se-iam, de imediato, o grande tema da fotografia e logo foram popularizados pelo francês André Adolphe Eugène Disdéri (1819-1889) e sua técnica do carte-devisite (1854), possibilitando que numa única placa sensivel fossem feitas até 8 imagens pequenas, reduzindo efetivamente os custos, o que facilitava a produção e a partilha da própria imagem (Aubenas, 1997). Passariam mais algumas décadas até que, nos fins do século XIX, surgisse a Kodak, tornando a produção de fotografia ainda mais simplificada e acessível. Com a proposta de "aperte o botão, nós fazemos o resto", milhares de fotógrafos amadores se espalharam pelo mundo, criando um enorme álbum fotográfico imaginário que alimentou, desde então, um mundo feito de imagens. Um desejo comum fez com que os homens partissem ao mundo para registrá-lo. Se hoje os desejos são múltiplos e incontornáveis, algo que resta do surgimento da fotografia talvez possa nos dar uma pista de que ela, juntamente com as ideias de progresso do século XIX e a consequente aceleração do tempo, criou um novo anseio de não perder nada, de guardar: a 
fotografia inventou um meio - frágil, mas persistente - de salvar as coisas do esquecimento.

III.

A História da Fotografia (com maiúsculas) poucas vezes se ocupou das fotografias vernaculares, dando mais atenção, desde os seus primórdios, a fotografias com evidentes aspectos estéticos, artísticos e/ou históricos. Geoffrey Batchen (2000) se ocupou de fazer um levantamento da aparição desses estudos ao longo dos tempos, tornando irrefutável o fato de que, ainda que pouco pesquisado, esse tipo de imagem constitui a maior parte das fotografias produzidas sempre. Essas imagens falam, em primeira e última instância, do homem mesmo, da sua relação com o outro, com o tempo e com a memória. Se há algo de suma importância ao olhar essas fotografias é quanto ao desejo de serem produzidas, o que move essas imagens e as fazem circular, ou serem esquecidas. $O$ que verdadeiramente estamos a falar quando falamos de fotografias vernaculares é sobre o homem e seu gesto, sobre a construção da memória e mesmo do esquecimento. Hoje já é possível encontrar um número maior de pesquisas dedicadas a essas imagens, com suas especificidades e seu lugar próprio. Mas é preciso ir mais fundo nessas questões, porque talvez o que essas imagens queiram nos dizer seja do desejo primitivo do homem de fazer uma marca no mundo, de fazer algo permanecer. E, mais além, elas falam do nosso afeto, aquilo que nos vincula com o outro.

Sobre esses vínculos, Roland Barthes (1984, p. 146) escreverá: "Vivo a Fotografia e o mundo de que ela faz parte de acordo com duas regiões: de um lado, as Imagens, de outro, minhas fotos". As "minhas fotos" são justamente as fotografias familiares, afetivas, amorosas, imagens que nos fazem pertencer, ter um rosto; imagens da vida comum feitas normalmente por amadores ou fotógrafos desconhecidos. Dentro do contexto artístico e acadêmico, falamos o tempo todo das "Imagens" (mantenho a maiúscula de Barthes), de suas ficções e seus artifícios; apuramos nosso olhar para olhá-las e, ainda que sejamos muitas vezes por elas arrebatados, podemos ainda nos manter a uma certa distância, à margem de um perigo maior. Mas, e diante das nossas fotos? E diante do porta-retratos que guarda o rosto ausente, no qual nos pegamos, de repente, a acariciar sua pele de grãos de prata?

Depois da morte da mãe, Barthes buscou-a em diversas fotografias, mais recentes, mais antigas. Não a encontrava em nenhuma, e seu luto era profundo e devastador (Barthes, 2011; Santos, 2016). Até que um dia ele viu a foto do jardim de inverno, em que aparecia uma menina de cerca de 5 anos de idade e seu irmão. Ali, ele, enfim, reconheceu a mãe. Uma mãe que ele jamais vira daquela forma, daquele tamanho, naqueles trajes. Mas era a mãe reconhecível, a mãe que ele sentiu ser a sua. A velha mãe que há pouco tempo morrera não se assemelharia com a criança do jardim de inverno para um olhar comum. Por isso, Barthes não nos mostra a imagem. É preciso o olhar do filho órfão para fazer reviver a mulher ausente no corpo de uma criança impressa no papel.

A fotografia inaugura um novo tipo de crença na imagem, no sentido de nos fazer acreditar em algo, numa passagem, na impressão da luz, em algo que esteve em contato, próximo ao corpo amado. Tal como no cadáver, corpo-imagem refeito à semelhança do vivo, há, no retrato daqueles 
que amamos, alguma presença, um rastro, o que Barthes (1984, p. 121) chamou de "vínculo umbilical", a luz como meio carnal, "uma pele que partilho com aquele ou aquela que foi fotografado".

Desconfio de que as fotografias amorosas sejam uma chave de compreensão da relação mais primitiva do homem com as imagens. Lembro-me de Régis Debray a se perguntar: "Em suma, por que motivo há imagem em vez de nada?" (Debray, 1993, p. 21). Do que estivemos tentando nos salvar desde os primórdios dos tempos? Sim, do desaparecimento, tentando deixar uma marca sobre a pele do mundo. Mas essa simples resposta não nos mostra os tortuosos percursos do homem para manter-se visível, para deixar seu traço de visibilidade quando a morte leva quase tudo.

IV.

Louis-Vincent Thomas, antropólogo da morte, relata-nos uma prática e uso do duplo do cadáver numa cerimônia dos Torajas, grupo étnico da Indonésia:

Por vezes, a figuração - substituta do traço -, que ambiciona tornar o morto presente, toma a forma da efígie. O Tau-tau dos Torajas (ilhas Celebes), forjado em madeira de jaqueira, deve assemelhar-se o mais possivel ao defunto (mesmo sexo, mesma altura, mesmo rosto); o que não exclui possiveis embelezamentos. Vestida com os trajes do morto, adornada de joias, colares e braceletes, a estátua segue sendo o objeto de diversos ritos, que consistem, alternadamente, em animá-la e levá-la à morte, chorá-la, consagrá-la. Ao final de uma longuíssima cerimônia, o cadáver, sepultado em sua mortalha, é alçado a uma plataforma acima da qual coloca-se o Tau-tau. Ambos comandam em seguida o sacrifício de búfalos, e receberão suas respectivas participações nas oferendas. Finalmente, enquanto o cadáver junta-se definitivamente a seu jazigo, sua figura é exibida, para todo o sempre, o mais perto possivel do túmulo. Para os Torajas, a efígie se torna mais do que um objeto associado ao morto; ela é, "se não o defunto, ao menos seu duplo visivel" (Thomas, 1991, p. 503-504). ${ }^{3}$

Interessante observar o espaço partilhado entre o cadáver e seu duplo, presidindo o ritual, recebendo as oferendas. Mas o que permanecerá visivel, doravante, será a efígie de madeira, que velará os mortos e os vivos, dando um novo rosto ao rosto que desapareceu, um corpo tangível ao corpo envolto em tecido, invisibilizado pelo grupo social. A figura em madeira guarda o morto, ao mesmo tempo que o substitui, numa dupla função que protege o sobrevivente da ideia do fim. A estátua do homem morto é agora quem lhe dá um corpo - corpo reificado pelo olhar dos vivos,

\footnotetext{
3 "Parfois la figuration - substitut de la trace - qui vise à rendre le mort présent prend la forme de l'effigie. Le Tau-tau des Toradja (îles Célèbes) façonné en bois de jacquier, doit ressembler le plus possible au défunt (même sexe, même taille, même visage); ce qui n'exclut pas les embellissements possibles. Revêtue des habits du mort, parée de bijoux, colliers et bracelets, la statue demeure l'objet de nombreux rites qui consistente tour à tour à l'animer et à la faire mourir, à la pleurer, à la consacrer. Au terme d'une très longue cérémonie, le cadavre enseveli dans ses linceuls, est hissé sur une plate-forme au-dessous de laquelle est placé le Tau-tau: tous deux président alors aux sacrificies de buffles et recevront leur part d'offrandes. Enfin, tandis que le cadavre rejoint définitivement le sépulcre, on exhibe pour toujours sa figure le plus près possible du tombeau. Pour les Toradja, l'effigie devient plus qu'un objet rituel associé au mort; elle est 'sinon le défunt, du moins son double visible'". Tradução nossa.
} 
pela memória, pelo gesto de concepção de um duplo que porta as mesmas roupas, o mesmo sexo, o mesmo rosto. Thomas falaria depois que a potência da memória "oferece, com o apoio do simbólico, um paliativo à angústia do não-ser e à ruptura da perda" (Thomas, 1991, p. 507). ${ }^{4}$ Não estamos muito distantes disso; nossos túmulos estão repletos de fotografias e nomes. Mais do que de uma luta contra o esquecimento, trata-se de devolver um corpo, um rosto, uma identidade àquilo que está em estado de invisibilidade, cuja carne corrompe-se no tempo. Reinventar os corpos é o que homem tem feito ao longo de sua história. Somos portadores desse gesto.

É preciso, de imediato, lançar o olhar ao sujeito que produz e utiliza as imagens, elas que Ihe provocam uma constelação de tempos onde ausência e presença jogam simultaneamente. Quer se trate do vivo ou do morto, as imagens falam, sobretudo, daquele que as manipula, que projeta o outro e a si mesmo nelas. Imagens podem vir de objetos físicos, podem ser geradas mentalmente, podem, inclusive, ser produzidas por camadas e camadas de outras imagens (Belting, 2005). O ponto central é o seu uso. As imagens das quais tratamos são imagens entre o visível e o invisível, imagens que se dão em uma materialidade específica, em um meio, mas cuja função ultrapassa os limites da visibilidade, jogando principalmente com o que não é dado a ver, com o invisível, que também é imagem, embora operado em outro lugar. Entre o visível e o invisível resta o homem, que é quem manipula essas instâncias na sua concepção e uso das imagens.

A ideia de um jogo permanente entre visível e invisível na fotografia nos leva a pensar, simultaneamente, num gesto de aparecimento e desaparecimento do outro da imagem. Ele está lá, é visível, tangível. Mas para que ele retorne, para que apareça, tornando-se presente no tempo atual, é preciso aquilo que mencionamos como uma nova ideia de crença via imagem; acreditar que, para além do papel e dos pixels, o corpo ausente se vincula ao meu, agora.

Falando sobre a preparação e apresentação do cadáver, no âmbito de um rito funerário como nos é familiar, Louis-Vincent Thomas (1985, p. 155) nomearia o momento de exibição do corpo - higienizado, conservado e embelezado - como o de uma "presentificação". Não se trata, portanto, de uma mera apresentação do corpo ou representação do que era o vivo, mas de um tornar presente alguma instância do sujeito, da pessoa. Como se, no corpo simbólico refeito sobre o cadáver, algo de uma presença retornasse. Esse termo - presentificação - é, portanto, eleito aqui para se pensar a especificidade da representação do corpo do morto depois que o corpo original (o corpo de carne) desaparece da vista. O cadáver é o primeiro corpo reinventado daquele que morre - porque o que desejamos nele ver não é sua substância orgânica, mas a pessoa. Um processo simbólico e subjetivo se instaura entre o cadáver e eu, somente assim posso constituir outro corpo - corpo ainda em relação comigo. Para tanto, outra ideia soma-se ao termo de Thomas. Hans Belting falaria da imagem e seu suporte - o medium -, como um processo, a ser estabelecido, de "animação":

Desde épocas remotas, os humanos são seduzidos pela comunicação

\footnotetext{
4 "offre, avec l'appui de la symbolique, un palliatif à l'angoisse du non-être et à la rupture de la perte". Tradução nossa.
} 
com imagens como se fosse com corpos vivos, e pela aceitação daquelas como substitutas destes corpos. Em tal caso, na verdade, nós animamos seu suporte com o intuito de experimentar as imagens como vivas. Essa animação é a nossa parte no processo, assim como o desejo do nosso olhar é a parte do suporte em questão. O suporte é o objeto da animação; a imagem é o objetivo. Animação, em seu sentido ativo, comunica a ideia de uso das imagens melhor do que percepção. Este último termo aplica-se à nossa atividade visual em geral, no dia-a-dia. Artefatos visuais dependem, porém, de um tipo específico de percepção - percepção de imagens como se fossem corpos, ou representantes dos corpos -, isto é, percepção de tipo simbólico. O desejo por imagens precede a invenção de seus respectivos suportes (Belting, 2005, p. 306-307). ${ }^{5}$

Para além da percepção dos elementos visuais, seria preciso realizar o procedimento de animação do medium, para assim experienciar as imagens como um corpo vivo. O suporte poderia ser pensado como "corpos técnicos ou artificiais concebidos para substituir os corpos através de um procedimento simbólico. Imagens vivem, como somos levados a crer, nas suas mídias tanto quanto vivemos em nossos corpos" (Belting, 2005, p. 306). ${ }^{6}$ Essa comparação coloca imagem e corpo (a sensação de pertencer a um corpo, o que poderíamos chamar aqui de a pessoa) em um campo comum; enquanto, por outro lado, medium e corpo (o da carne, o suporte) estão postos à parte. A pessoa é, portanto, quem anima a carne - o que lhe dá vida, alma. Desaparecido o corpo fisiológico, com a perda de sua função-suporte, outros corpos são chamados a lhe substituir, para que a pessoa, seu corpo simbólico e afetivo, continue a existir.

O corpo, aqui, é a ideia de um duplo corpo: o corpo da carne, da pele, corpo do vivo que, na morte, tornar-se-á invisível - menos por um desaparecimento próprio do que pela urgência dos sobreviventes em fazer-lhe desaparecer -, e o corpo que lhe substitui, não mais o da carne, o fisiológico, o cadáver. É o corpo da relação com o outro; corpo social e afetivo. Portanto, simbólico, construído fora do corpo de carne, para o qual este é uma espécie de suporte, mas, ao mesmo tempo, sua imagem e seu lugar de contato. Este é o corpo que, não sendo mais encarnado, é constituído por seu rastro, seu vestígio, sua imagem, seu nome, qualquer elemento que restitua alguma corporeidade ao que desapareceu. Corpo recomposto como um boneco de madeira esculpido, em que colocamos as mesmas roupas, o mesmo sexo, o mesmo rosto.

A nossa relação com o mundo é física, passa pela pele, pela visão, olfato, tato, paladar, pelas sensações mais diversas que se produzem no corpo a partir dos sentidos e da imaginação. Ainda que imagens povoem também um lugar invisível, elas tendem a tomar formas visíveis, tangíveis, com as quais nosso mundo se constrói. O mundo passa pelo nosso corpo, pela carne, pelos olhos e pelas mãos. Não é de se estranhar que desejemos lançar o imaginário em direção

5 "From early on, humans were tempted to communicate with images as with living bodies and also to accept them in the place of bodies. In that case, we actually animate their media in order to experience images as alive. Animation is our part, as the desire of our look corresponds to a given medium's part. A medium is the object, an image the goal, of animation. Animation, as an activity, describes the use of images better than does perception. The latter is valid for our visual activity in general and in everyday life. Visual artifacts, however, depend on a specific kind of perception - perception of images, as if they were bodies or in the name of bodies - that is, perception of a symbolical kind. The desire for images preceded the invention of their respective media". Tradução nossa.

6 "technical or artificial bodies designed for substituting bodies via a symbolical procedure. Images live, as we are led to believe, in their media much as we live in our bodies". Tradução nossa. 
ao palpável, imagens que possuam, também, corpos. Da mesma forma, não é de se estranhar que tentemos reavivar o morto na constituição de um novo corpo.

V.

Louis-Vincent Thomas, para além de seu longo trabalho na antropologia, foi um homem que se deixou expor na experiência íntima da morte. Em um de seus livros, ele se coloca, ainda que de passagem, como personagem enlutado no rastro do corpo de sua mulher:

Para tornar presente minha esposa, que perdeu a vida há dois anos, após quarenta e sete anos de felicidade conjunta, mais de cem fotografias dela, em todos os momentos de sua vida, revestem as paredes do apartamento. Isso me traz conforto, até mesmo serenidade, principalmente quando, iluminadas à noite, escuto as fitas cassetes que ela tanto apreciava; uma forma de ritual quase sagrado, de comunhão, em que o simulacro do traço tem um papel de terapia litúrgica. A imagem de sua morte, em que ela aparece calma e digna, não fica de fora, é diante dela que me recolho diariamente (Thomas, 1991, p. 504-505). ${ }^{7}$

As fotografias, as músicas, o sobrevivente. Assim, Thomas reconstitui diariamente a presença da mulher, em novos suportes repletos de ausências, mas cheios de rastros, traços, vestígios, nas imagens, nas memórias, mesmo na fotografia de seu corpo morto. Albert Piette, também antropólogo, faz da perda de seu pai um trabalho duradouro de escrita, em que tentava, diariamente, devolver-lhe um rosto, um corpo:

Meu objetivo era mesmo de fixar o rosto, os gestos, o comportamento de meu pai. Seria algo como fotografá-lo, já que eu tinha disponíveis muito poucas fotos recentes, e nenhum documento audiovisual em que pudesse vê-lo vivo e em movimento. A escrita tornava-se uma esperança de captar, guardar, para além da morte, o vivido e os traços de meu pai. Meu único recurso para assegurar-me uma nova forma de sua presença. $A$ única possível. Também sabia que era necessário fazê-lo rapidamente, que essa presença dependeria da minha memória, das minhas lembranças, da minha capacidade de escrever e de encontrar as palavras precisas (Piette, 2003, p. 9-10). ${ }^{8}$

O trabalho de Piette é comovente, é possível sentir em seu texto a tentativa de restituição

7 "Pour rendre presente mon épouse qui après quarante-sept années de bonheur en commun a cessé voici deux ans de vivre, plus de cent photographies d'elle, à tous les âges de la vie, tapissent les murs de l'appartement. Cela m'apporte l'apaisement, voire la sérénité surtout quand, éclairées le soir, j'écoute en les contemplant les cassettes qu'elle affectionnait; manière de rite quasi sacré, de communion où le simulacre de la trace joue un rôle de thérapie liturgique. La figure de sa mort où elle apparaît calme et digne n'est pas épargnée, c'est devant elle que je me recueille quotidiennement". Tradução nossa.

8 "Mon objectif était bien de fixer le visage, les mimiques, les comportements de mon père. Ce serait comme le photographier alors que je disposais de très peu de photos récentes et d'aucun document filmique dans lequel j'aurais pu le voir vivre et bouger. L'écriture devenait un espoir, celui de capter, de garder, au-delà de la mort, le vécu et les traits de mon père. Ma seule ressource pour m'assurer une nouvelle forme de sa présence. La seule possible. Je savais aussi qu'il fallait faire vite, que cette présence serait dépendante de ma mémoire, de mes souvenirs, de ma capacité d'écrire et de trouver les mots justes." Tradução nossa. 
de uma memória inteira, amorosa, em direção à qual ele pudesse voltar para encontrar o pai. Ele escreveu, durante quase 5 anos, cerca de 500 páginas. "Pela escritura da vida passada do meu pai, eu tento reencontrar e fixar seus traços. Atribuo a ele assim uma outra forma de presença" (Piette, 2005, p. 15). ${ }^{9}$ Presença que se desenha no texto como memória, como objeto - os papéis acumulados -, como gesto de se colocar diariamente na escrita. Para o autor, escrever é menos o ato de lembrar, mas, antes, de atestar que as coisas aconteceram, como uma prova de existência, como quem faz uma fotografia, para que o texto, depois, ajude a manter uma lembrança. A escritura não assegura uma continuidade, mas marca um traço do pai; a escrita como um ato, ritual íntimo e privado da memória. O que o autor procura, mais do que a veracidade de uma cena descrita, é a precisão de um determinado detalhe, o mínimo, uma expressão do rosto do pai. Mesmo o efeito do nome pronunciado, como no caso de uma missa onde o padre o profere, produz uma força de presença que somente a pessoa vinculada amorosamente ao morto poderá sentir.

Ao referir-se a meu pai, o padre o reaproxima: assim, eu o vivo. É em minha direção que ele o reaproxima. Pois essa força da palavra apenas faz sentido, obviamente, para aquele que amou. É preciso amor para que o objeto que representa o ausente, o gesto que o designa, ou a palavra que o rememora o tornem presente. É a magia humana do objeto, da palavra ou do gesto que torna presente o ser amado (Piette, 2005, p. 27-28). ${ }^{10}$

O amor, a magia, a presença - o tornar presente, esse sentido dado pelo termo presentificação, só é possível no afeto: o amor como agente do estado mágico dos objetos que nos ligam ao morto, que lhe reconstrói um corpo. Se a fotografia de um ser amado guarda algo de sua presença imediata, convocando nossa memória e nosso corpo, a fotografia de um desconhecido, ou de alguém a quem não somos vinculados amorosamente, permaneceria no terreno de uma mera representação. $O$ afeto provoca a magia da imagem: ele faz retornar qualquer coisa de perdido.

Piette se coloca no texto como um ser da experiência - tal como Thomas a falar de sua mulher. A antropologia, aí, abre espaço para um outro olhar, que envolve também o pesquisador em sua experiência íntima. Muitos textos teóricos confirmam a presença dessa intimidade, ao tratar tanto das fotografias familiares quanto da morte, como se esses assuntos convocassem, necessariamente, a própria experiência. Piette defende o uso do que ele chamou de "detalhes pessoais" como matéria de composição de um olhar sobre os outros e sobre si mesmo: "Ao mesmo tempo em que marginalizam a autoridade do texto científico, os dados pessoais constituem penso eu - uma via possível, talvez até necessária, em direção à compreensão de territórios tão privados como o luto e a crença". (Piette, 2005, p. 9). ${ }^{11}$ E Thomas escreveria, na abertura de um

9 "Par l'écriture de la vie passée de mon père, je tente de retrouver et de fixer des traces. Je lui confere ainsi une autre forme de présence". Tradução nossa.

10 "En désignant mon père, le prêtre le rapproche: je le vis ainsi. C'est vers moi qu'il le rapproche. Car cette force de la parole n'a bien sûr de sens que pour celui qui a aimé. Il faut de l'amour pour que l'objet qui représente l'absent, le geste qui le désigne ou la parole qui le rappelle le rendent présent. C'est la magie humaine de l'objet, de la parole ou du geste qui rend présent l'être aimé". Tradução nossa.

11 "Tout en décentrant l'autorité du texte scientifique, les détails personnels constituent - je le pense - une voie possible, voire nécessaire, à la compréhension de domaines aussi privés que le deuil et la croyance". Tradução nossa. 
dos seus livros, dedicado à esposa, lamentando o fato de que ter ido tão longe em seus estudos sobre a morte não the servira para nada:

A morte, eis que durante mais de trinta anos eu tento envolvê-la, surpreendêla, desmontar suas estratégias, enganá-la. Sem que nada saiba sobre ela, mesmo tendo escrito entre duas e três mil páginas a seu respeito. Faço dela um objeto privilegiado de reflexão, mas ela se aproveita disso para me agredir e me mutilar. De que serve ser tanatologista? (Thomas, 1991, p. 9). ${ }^{12}$

A morte de um próximo é uma experiência particular e incompartilhável. O espaço vazio que fica na casa, a estranha sensação de deixar o morto sozinho no cemitério, a brutalidade de um corpo que desaparece. As palavras - vazias como a casa - parecem não alcançar ninguém. Um mundo mágico começa a se tecer, então, no sobrevivente, em suas memórias, nos objetos que restaram, nas fotografias, cartas, fitas cassetes, filmes. Ele começa a compor um novo corpo para ocupar o lugar vazio. Paul Auster, logo após a morte do pai, começa um trabalho de escrita. Vagando entre a casa, os objetos e as memórias, também as de sua própria infância, na coleta de materiais diversos que pudessem dar um corpo - agora escrito - ao homem morto, Auster escreve para manter o pai presente. Por isso, ele teme o fim da escrita, perdendo-se no tempo dela, adiando a palavra para adiar o silêncio, para afastar a morte definitiva do pai.

Nada durante vários dias...

Apesar das desculpas que inventei para mim mesmo, compreendo o que se passa. Quanto mais me aproximo do fim daquilo que sou capaz de dizer, mais me torno relutante de dizer o que quer que seja. Tenho vontade de adiar a hora de terminar e, desse modo, me iludir com a ideia de que estou apenas começando, que a melhor parte da minha história ainda está por vir. Por mais inúteis que essas palavras pareçam, elas no entanto se colocaram entre mim e um silêncio que continua a me apavorar. Quando eu ingressar nesse silêncio, vai significar que meu pai desapareceu para sempre (Auster, 1999, p. 77).

Ele falaria, ainda, das fotografias que encontrara na casa do pai, objetos que ele perscrutou à exaustão, como se pudessem lhe revelar alguma verdade oculta: "estudei cada uma delas com toda a atenção, assimilando os menores detalhes, a sombra mais insignificante, até que todas as imagens se tornassem parte de mim" (Auster, 1999, p. 21). Para Auster, as fotografias reafirmavam a presença física do pai no mundo. Muitas delas ele jamais havia visto, especialmente as da juventude do pai, o que lhe dava a sensação de encontrá-lo pela primeira vez, de acompanhar uma vida nova; portanto, afastada da morte.

12 "La mort, voici plus de trente ans que je tente de la cerner, de la surprendre, d'en déjouer les stratégies, de ruser avec elle. Sans rien en savoir bien qu'ayant écrit à son propos entre deux mille et trois mille pages. J'en ai fait un objet privilégié de réflexion; mais elle en profite pour m'agresser et me mutiller. A quoi sert-il d'être thanatologue?" Tradução nossa. 
Enquanto eu mantinha essas fotos diante dos olhos, enquanto eu as examinava com toda a minha atenção, parecia que ele ainda estava vivo, mesmo na morte. Se não vivo, pelo menos não estava morto. Ou melhor, suspenso de algum modo, encerrado em um universo que nada tinha a ver com a morte, no qual a morte nunca poderia entrar (Auster, 1999, p. 21).

Nelas, nas fotografias, não havia a morte, embora só houvesse ela. Em um jogo ambíguo, as imagens brincam de restituir algo, como as palavras. Depois da morte do meu pai, li todas as cartas que ele escreveu, na juventude, para a minha mãe; li seus antigos diários de viagem; encontrei gravações de telefonemas para os pais, que viviam no exterior, em um dos quais ele contava para a mãe que eu havia nascido. O meu pai estava morto, mas eu passara a conhecer um outro homem, outro pai, aquele que ainda não era o meu pai. Os objetos trouxeram a nítida sensação de que um homem reverbera na existência mesmo depois de sua morte, que eu poderia ainda conhecê-lo de tantas outras formas que não dependiam mais do seu corpo efetivo no mundo, mas dos seus rastros e da relação que eu agora estabelecia com eles. Este texto percorre, então, esses corpos inventados, retratos, restos, vozes, uma mecha de cabelo, um punhado de flores secas. Desde o seu advento, a fotografia, entre outros artifícios, tenta responder à demanda do sobrevivente de substituir, em alguma instância, o corpo desaparecido.

VI.

Dentro do amplo universo dos retratos familiares, há dois grupos de imagens particularmente interessantes para se pensar a questão dos vínculos entre vivos e mortos: as fotografias memoriais e as fotografias post mortem..$^{13}$

O conceito de fotografias memoriais é aqui empregado para falar das imagens utilizadas para fins funerários sem mostrar um cadáver - são retratos dos que hoje estão mortos, mas feitos quando ainda eram vivos, podendo ser também imagens de objetos, como da coroa de flores de um velório, um artigo pessoal, a sepultura. Um exemplo comum do que chamamos de fotografia memorial é o retrato do homem ainda vivo colocado no túmulo do homem agora morto: sua fotografia se transforma em uma imagem funerária no instante exato em que o homem morre.

A fotografia post mortem, também conhecida como fotografia mortuária, foi uma prática popular e comum ao longo do século XIX e primeiras décadas do XX, tornando-se mais silenciosa e íntima a partir de então. Essas imagens mostram o morto, isto é, o cadáver mesmo. Muitas vezes ele aparece como um ser adormecido, embalando a ideia cristã da morte como a de um sono profundo. Mas é possível encontrá-los também, os mortos, em caixões e camas velatoriais, ou, mais surpreendentemente, como se estivessem vivos, sentados sozinhos ou acompanhados por seus entes, de olhos fechados ou abertos, muitas vezes com as pálpebras reabertas por uma camada

\footnotetext{
13 Por questões de direito de uso das imagens, não exibiremos essas fotografias no artigo. Sugiro fortemente a visita ao website <http://thanatos.net/>, que possui uma grande coleção dessas imagens familiares utilizadas e/ou produzidas em contexto funerário. E possível conhecer também uma parte da vasta coleção de Stanley Burns: Disponível em: <http://www.burnsarchive.com/EXPLORE/HISTORICAL/Memorial/index.html>. Acesso em: 27/04/2017.
} 
posterior de pintura. $O$ ato fotográfico, muitas vezes partilhado entre vivos e mortos, tornava-se um instante de relação, um meio possível de ainda interagir com o morto. Funcionando tanto como uma homenagem, como uma prova de existência, a fotografia do corpo morto evidenciava sua passagem pela vida e, especialmente, o afeto e o desejo de rememoração dos sobreviventes. ${ }^{14}$

Poderíamos pensar no espaço partilhado da imagem como sendo também o lugar do luto, que, em primeira instância, é como o vivo pode dar um lugar ao morto. Entendemos melhor, ao estudar a história da relação que o homem estabeleceu com a morte ao longo dos tempos, que o trabalho de luto é, na realidade, o lugar que o vivo pode dar-se a si mesmo para lidar com a morte do outro. Porque a morte é sempre dessa ordem estrangeira, de uma alteridade absoluta e voraz, e quando estamos em contato imediato com ela, com o que ela nos leva, resta encontrar o que ela fez de nós, os sobreviventes. O luto é feito pelos vivos e para os vivos, para que haja um meio de sobrevivência diante da brutalidade do desaparecimento. Portanto, pensamos aqui o luto como um vínculo - ativo e potencialmente permanente - que os vivos estabelecem com os seus mortos através da construção de práticas e rituais que ajudam a dar um lugar de visibilidade e presença ao que desapareceu. A fotografia, no geral, seja de vivos ou de mortos, é um dos meios essenciais de permanência do corpo, da imagem do corpo, tal como seriam também os monumentos, os túmulos, mechas de cabelo, dentes de leite, uma peça de roupa, objetos pessoais do morto. Todos esses elementos ajudam a corporificar novamente aquilo que desapareceu, como prova, mas também, e principalmente, como lugar de contato, afeto e intimidade. A ideia de luto, aqui, não diz respeito somente a um estado temporário de dor e elaboração psíquica e emocional, mas à particularidade da conexão do vivo com o seu morto.

A relação do homem com a morte sofreu profundas mudanças ao longo dos tempos. É inevitável evocar Philippe Ariès (1981) e sua historiografia que nomeia a atitude atual perante a morte de "selvagem", enquanto a do passado era "domesticada". No primeiro caso, a morte é pensada como um perigo que precisa se afastar da sociedade, enquanto no segundo ela é familiar e comum. Mas o sociólogo Patrick Baudry, em uma fala aparentemente relacionada a Ariès, dirá que:

Não existe uma naturalidade na relação com a morte que nós pudéssemos
ter perdido. Toda sociedade constrói, diante de questões numericamente
limitadas - que fim dar ao cadáver, que gestos realizar para dar significado
à perda, que sentido atribuir ao desaparecimento de quem estava aqui? -
e a partir de um estoque igualmente limitado de respostas culturalmente
disponíveis, isto é, capazes de fazer sentido, uma elaboração da relação
com a morte. Trata-se, portanto, de redimensionar o evento puramente

${ }^{14}$ A fotografia post mortem é tema de algumas pesquisas no Brasil, em geral levando em consideração mais os seus aspectos históricos e sociológicos. Alguns dos pesquisadores que se envolveram com esse assunto são: Titus Riedl (2002), concentrando-se no Nordeste, especialmente na região do Cariri; Luiz Lima Vailati (2005), que fez um estudo sobre as fotografias de crianças mortas no Brasil oitocentista; Miguel Augusto Pinto Soares (2007) e Sandro Blume (2013), ambos pesquisando a fotografia mortuária no Rio Grande do Sul; Deborah Borges (2013), que foca seus estudos em uma pequena cidade de Goiás. Em termos mais estatísticos, Mauro Koury (2006) fez uma longa pesquisa sobre as atitudes perante a morte no Brasil contemporâneo, especialmente no que tange as questões do luto e seus rituais. A partir de uma pergunta adendo em um amplo questionário, ele tentou averiguar a sobrevivência do uso da fotografia mortuária na última década do século XX. Nessa pesquisa, realizada entre os anos de 1994 e 2001, ele entrevistou 1304 pessoas nas 27 capitais brasileiras, obtendo uma resposta afirmativa de 271 informantes. Apesar de apenas $20 \%$ dos entrevistados afirmarem o uso da fotografia post mortem, esse número surpreende, e nos indica uma sobrevivência efetiva da prática. 
biológico - a interrupção de uma existência, o término de uma vida - dentro de uma lógica de sentido que envolva o próprio sentido da sociedade em questão. A cultura - no sentido antropológico do termo - consiste em dar sentido, e principalmente em dar sentido ao que extrapola a significação (Baudry, 2001, p. 30). ${ }^{15}$

Portanto, o fator essencial é a significação que cada cultura e cada época dá à morte, ao estatuto do morto e à relação com ele estabelecida. No século XIX, a morte ainda integrava o tempo e os ritos familiares com uma visibilidade que não existe mais hoje, quando, curiosamente, tudo é fotografável, menos a morte. Ou, melhor, menos a morte que nos afeta. Para a maioria das pessoas, ainda é impensável uma mãe que segure deliberadamente sua criança morta nos braços para a última imagem. Mas há algo disso que sobrevive em algumas situações, como no hábito de se fotografar o bebê natimorto. ${ }^{16}$ É inclusive aconselhado aos pais, que perderam assim os seus filhos, a fazer esta primeira e última imagem, como um instrumento auxiliar do luto, guardando a memória do que quase não chegou a existir. A fotografia torna-se, doravante, a prova de uma existência tão breve quanto tangivel.

A era digital também tem tornado mais explícita a prática de fotografias em contexto de luto, seja com imagens simbólicas que não chegam a mostrar o morto, como em imagens com o próprio cadáver, embora seja muito mais comum mostrar o corpo quando se trata de um bebê natimorto ou morto em gestação. Através das redes sociais, dos memoriais online e das práticas de compartilhamento, é possível perceber uma maior evidência na circulação atual desse universo de imagens (Morcate, 2012).

Nas fotografias post mortem, gestos familiares e amorosos trazem os corpos para diante do dispositivo, que lhes responde a demanda de guardar o ser amado. O ato fotográfico participa, portanto, como uma das etapas de despedida do corpo original, inventando, de agora em diante, um outro corpo. Fazer a imagem de um cadáver é mantê-lo imóvel neste ponto do processo: tornando o cadáver estático, ele não perecerá.

Em geral, as crianças foram o principal assunto da fotografia post mortem. No século XIX, a taxa de mortalidade infantil era muito alta. Por vezes, em decorrência de uma doença que afetava uma das crianças, uma família perdia todos os seus filhos no intervalo de dias. Para além dos fatores da grande mortalidade, as crianças, sendo ainda muito pequenas, em geral não haviam tido a chance de serem fotografadas. A fotografia post mortem era então um bem muito desejado quando a criança morria, já que a única forma de guardar o pequeno corpo. Entre crianças sozinhas, com seus irmãos, seus pais ou no colo de suas mães, uma ampla gama de possibilidades surgiu para responder à demanda de uma sociedade que encontrara na fotografia um meio de manter

15 "Il n'existe pas de naturalité du rapport à la mort que nous aurions perdue. Toute société construit, devant des questions limitées en nombre - quel destin donner au cadavre, quels gestes accomplir pour signifier la perte, quel sens donner à la disparition de celui qui était ici ? - et à partir d'un stock tout également limité de réponses culturellement disponibles, c'est-à-dire capables de faire sens, une élaboration du rapport à la mort. Il s'agit donc de reprendre l'événement tout biologique - la cessation d'une existence, la terminaison d'une vie - dans une logique de sens qui implique le sens même de la société considérée. La culture - au sens anthropologique du terme - consiste en une mise en sens: et surtout en la mise en sens de ce qui excède la signification". Tradução nossa.

16 Sugiro a visita ao website "Now I lay me down to sleep", um projeto que oferece serviço fotográfico gratuito a pais de bebês natimortos ou mortos em gestação: <https://www.nowilaymedowntosleep.org/> 
um traço, uma sombra, a imagem do outro presente. Se hoje a ideia de fotografar um morto nesse tom amoroso e familiar - parece distante e mórbida, no século XIX as pessoas usavam essas imagens da mesma forma que as outras fotografias que possuíam, "montadas e penduradas em quartos e salas de estar, coladas em álbuns, enviadas a parentes, colocadas sobre a lareira, carregadas em carteiras, e assim por diante" (Ruby, 1995, p. 159). ${ }^{17}$

Segundo o antropólogo Jay Ruby, a idade moderna ocidental viu, desde seus primórdios, a proliferação de retratos do vivo e do morto (nos meios sociais mais ricos e poderosos), respondendo ao desenvolvimento de uma ideia de individualismo, secularismo e do florescimento do status social (Ruby, 1995, p. 27). A prática de fotografar o morto veio de uma tradição mais geral de se retratar o morto, uma ideia tão antiga e conhecida como a do retrato mesmo. $O$ que a fotografia pôs em causa foi sua capacidade técnica de representar de forma "mais fiel" a realidade, o que conduziu, e de alguma forma, a imagem da morte e do morto para uma linha mais próxima do espectador, com menor possibilidade de encenações. Entretanto, a fotografia é um campo prolífero de ficções, narrativas encenadas, imagens duvidosas. Mas sua essência originária - também a crença que embalou fortemente seu advento - diz respeito à cópia que ela supostamente faria da realidade. Em relação à pintura, a fotografia, por um lado, barateou os custos da produção de um retrato; por outro, anunciou a promessa de uma proximidade mais efetiva com o seu referente, já que o "copiava". O impacto disso para a disseminação da fotografia post mortem foi, provavelmente, determinante nessa época ligada a valores românticos, em que as práticas do luto tomaram grande proporção.

As fotografias post mortem tornaram-se, ao longo do século $\mathrm{XX}$, uma prática em desaparição, ou, como sugere Jay Ruby, uma prática em silenciamento, tornada menor e mais secreta. Audrey Linkman (2011) indica a nova atitude fotográfica que se esboçou no correr desse tempo, aparentemente contrária à prática post mortem, mas curiosamente semelhante: a morte se tornou menos a catalisadora de fotografias mortuárias e mais uma condição geradora de um número cada vez maior de registros visuais do vivo. Celebrando a vida e cada um de seus instantes, a fotografia familiar contemporânea escondeu o rosto do morto, mas jamais deixou de falar justamente dela, da morte, e do medo que ela produz de algo ser perdido. Linkman sugere que o discurso do "lembrar-se de alguém como era" - o que significa: vivo - será o mais recorrente, incluindo, em muitos casos, o evitamento da visão do corpo morto (2011, p. 148). A vida e sua celebração são os novos anteparos da morte, mas, de forma paradoxal, falam justamente dela. A palavra proibida é a fonte do gesto. Evitando-a, a morte volta, permanece presente nas entrelinhas da coleção vertiginosa de imagens. O excesso de fotografias do vivo suprimiu a imagem do morto, mas ambas denunciam o mesmo terror ao desaparecimento.

VII.

Depois de refletir sobre os gestos dos vivos para tornarem presentes os seus mortos,

\footnotetext{
17 "mounted and hung in parlors, bedrooms, and living rooms, glued in albums, mailed to relatives, placed on top of mantels, carried in wallets, and so on". Tradução nossa.
} 
pensemos também sobre como eles, os vivos, tentam fazer-se presentes. Os cemitérios são lugares de memória e encontro, não somente onde o vivo materializa uma instância corporal do morto, mas onde ele se coloca como presença ao outro. As flores sobre as lápides, as inscrições amorosas, as pedrinhas que marcam passagem e memória: o vivo exibe-se para o morto, mostra a ele seu ato de lembrar como desejo de também ser lembrado, olha para ser olhado. Ele constrói para si um espaço para estar diante do morto, seu nome, retrato, a imaginação dos restos mortais como corpo inteiro, intacto, somente invisibilizado. O vivo se faz presente para o morto, mostra o seu rosto. "Não me esqueça" - ressoam as vozes frágeis e silenciosas pelo cemitério. O desejo de não esquecer é também o desejo de não ser esquecido. Talvez o vivo tenha inventado de colocar retratos na sepultura para ser diretamente olhado pelo rosto vazio do morto.

Mas as fotografias do vivo, tais como as do morto, mostram sempre um outro corpo. Corpo de metal, vidro, papel, pixel, corpo no qual tentamos projetar a presença do outro. Entretanto, muitas vezes, a mera visibilidade de um rosto não nos diz nada. Lembremo-nos da busca barthesiana pelo rosto da mãe, encontrado somente na dessemelhança de um rosto de criança. É do ar que se trata, este que não é dado na materialidade de objeto algum, que escapa sempre, que está fora. Patrick Baudry (2001) diria que as fotografias e outros registros limitam a memória efetiva do morto e que nossa verdadeira relação com ele está em outro lugar, não margeável, não controlável pela lembrança de um acontecimento - que, em geral, é o que uma fotografia nos dá.

Talvez seja a imagem, antes de tudo, uma mera possibilidade de ativação da memória, aquilo que traz, por vias incertas, um ar do outro, um rastro de presença. As fotografias são objetos melancólicos, que fingem restituir algo, prometendo um corpo, uma volta, mas que logo escapam, deixando-nos sós. Enquanto elas exibem uma situação, um evento com data e local específicos, a memória amorosa do morto ronda outro lugar, perdida entre lembranças e esquecimentos, mas viva, em contínua transformação. Portanto, a relação mais legítima que podemos estabelecer com os nossos mortos não está nas coisas: seus objetos, seus restos, suas fotografias, o registro de sua voz. Não é também um caráter puramente prático o que determina a relação com o morto, as visitas aos cemitérios, os gestos memoriais. Segundo Baudry, essa relação é sempre enigmática, jamais previsível por atos e/ou objetos, locais, lembranças tangíveis e controláveis, mas por elementos que emanam da própria vida. Não se pode decidir o que lembrar e o que esquecer, todas as ações e sensações são simultâneas e inacessíveis no desenrolar do tempo. A relação com o morto está por aí, nesse meio caminho, na vida que insiste em transformar tudo, na memória ativada por algo ou por nada, por uma sensação particular que, de repente, escapa da correnteza feroz do esquecimento.

Por fim, compreendemos que o que verdadeiramente buscamos nas imagens amorosas está irremediavelmente fora delas. Barthes (1984, p. 86) diria que o punctum de uma imagem - aquilo que fere, que lhe escapa - faz criar, adivinhar, um campo cego, lá onde, para além de suas bordas, os personagens continuam existindo, numa vida exterior ao próprio retrato. Mas, são elas mesmas, as imagens, em sua materialidade (o que Belting preferiria chamar de "medialidade"), que podem provocar um choque, um encontro, incorporando uma presença, geralmente quando estamos distraídos. Isso, certamente, depende mais do nosso próprio corpo e de seus arredores, de nossa 
disposição sensível ao encontro, do que da própria imagem. Ela dá uma pista, ela não diz muito, mas, de repente, estamos surpreendentemente mergulhados em sua dimensão fantasmática.

VIII.

As fotografias, tais como os monumentos, servem para lembrar ou para poder esquecer? Os objetos, as imagens, as palavras, os traços físicos no mundo, projetados no lugar dos verdadeiros corpos, dos desaparecidos, servem, afinal, para quê? Platão diria que o registro alimenta o esquecimento; a escrita seria a morte da memória, produzindo somente o gesto de uma rememoração (Gagnebin, 2005, p. 54). A fotografia que guarda um acontecimento, ou mesmo um rosto, é menos a memória da coisa mesma, e, antes, sua rememoração. Mas o próprio ato de lembrar - ou de ser pego, de surpresa, por algo, uma imagem, um cheiro, uma voz - pode dar acesso a uma invisibilidade da fotografia que não é mais da ordem da rememoração, mas de uma presença, de uma memória - pensada aqui como o momento de um encontro.

No longo panorama da história do homem com a morte e a imagem é fácil observar que vivemos numa época em que a morte é mais cotidianamente e espetacularmente visível, por meio de filmes, séries, jornalismo - os meios de entretenimento -, quando, contudo, mostrase tudo, menos o rosto do morto, a quem somos vinculados amorosamente. Talvez sejam os funerais das pessoas comuns, hoje, o rito menos fotografado e menos fotografável (embora não pareça estranha a filmagem e disponibilização do velório, como imagem, para qualquer lugar do mundo). O luto e a dor são elementos cruciais e, certamente, a fotografia se tornou uma prática tão banalizada que soaria como uma obscenidade fotografar deliberadamente o morto, um desrespeito no gesto de fazer uma mera imagem. Mas não acredito que se trate somente disso, há algo de uma visibilidade envolvida que parece ser central.

O que não desejamos ver para que não fotografemos o morto? Fotografar seria fazer o morto aparecer, como se a imagem the conferisse visibilidade? Ou seria fazê-lo desaparecer, tirando a visibilidade do cadáver em prol de uma presença, ainda, da pessoa? Por que não fotografamos mais o corpo morto, se tanto fotografamos o corpo vivo durante a sua existência? Não lidamos com o corpo morto de um ente amoroso como se fosse um mero cadáver, um resto biológico; pelo contrário, o beijamos, tocamos suas mãos, seu rosto, o olhamos com afeto. Então, por que haveria uma aura de interdição em sua fotografia, como se fosse uma atitude macabra e patológica, no mínimo de mau gosto? Restam as perguntas. É impossível chegar perto do que acontece na época em que vivemos; o correr do tempo dirá.

A morte daqueles que amamos foi se tornando invisível nas sociedades contemporâneas e imagino que, se fosse fotografada, ela seria dada a ver, perderia sua transparência e sua invisibilidade. Fotografar a morte é dar-lhe um rosto, tornar opaco o corpo do morto. Por algum motivo, temos evitado olhá-lo.

Mas estamos, hoje, inventando novas formas de relacionamento com os mortos: 
memoriais online, web velórios, huggable bears, ${ }^{18}$ mensagens ao além via redes sociais. Não estamos, portanto, evitando plenamente a ideia da morte. Mas a prática da fotografia post mortem povoa as mídias - o que uma simples busca na internet facilmente prova - agregada a palavras como bizarra, mórbida, macabra, freak, weird, creepy. Não parece freak falar com os mortos pelo facebook, mas guardar a imagem fotográfica de um morto que amamos está nas proximidades de uma aberração ou de uma patologia.

Por fim, resta notar que as fotografias amorosas - sejam do vivo ou do morto - são desejadas e guardadas como a promessa de sobrevivência de um traço, um rastro, como uma prova de existência e a possibilidade de representar, em algum lugar, o corpo ausente. Nessa representação, algo dele se faz presente, presentifica-se. Um novo corpo então é criado e animado, para que o vivo tenha esse outro com o que - com quem - se relacionar. Em uma espécie de comunhão entre corpos - presentes, ausentes e reinventados -, uma nova lógica de relação se faz. Como na Eucaristia cristã e em rituais primitivos, quando comer o corpo do outro é torná-lo parte de si, as imagens amorosas nos constituem sobre e sob a pele, a carne e a memória.

\section{Epílogo}

Se, naquela última imagem de seu corpo, eu não reconheci o meu avô, hoje eu compreendo que a estranheza não era anunciada pela fixidez do seu rosto morto, dos olhos fechados ou da miudeza de um homem que morre. O reconhecimento não está no lugar comum do rosto ou mesmo de uma expressão familiar. Barthes falaria de um ar e o ar do meu avô, depois de sua morte, eu somente encontrei em uma imagem que escapa a qualquer objetivo amoroso, a qualquer registro pensável dentro de um âmbito de afeto e intimidade. Mesmo tendo já conhecido a imagem antes de sua morte, foi somente depois dela que a grande ferida se abriu.

Pesquisando ruas pelo Street View, programa da Google que permite a visualização panorâmica de localidades ao nível do chão, um dia encontramos, meu irmão e eu, em uma bonita e estranha coincidência, o nosso avô. Seu rosto não é visível, está desfocado pelo programa que pretende preservar a identidade das pessoas aleatoriamente fotografadas. Mas todo o resto do seu corpo, sua roupa, seu caminhar, a sacolinha, a boina, o relógio, tudo é ele. Mesmo o jeito, o passo, a mão que se apoia no cesto de lixo, a cabeça baixa. Não se trata de uma única imagem, mas de uma sucessão delas, em que, a princípio, o vemos por trás, depois nos aproximamos, ficamos então ao seu lado e por fim passamos adiante. A data da imagem é de julho de 2011. Penso: ele ainda não estava doente. Vejo-o então percorrer a cidade novamente, hoje, vivo, a cidade reinventada pela imagem. Ali, ele é um velhote que caminha com sua sacolinha, tão vivo quanto nós. Não vejo o seu rosto, mas sinto profundo afeto pelo que a imagem me dá e, a seguir, caio brutalmente na ferida da fotografia: ela não me devolve nada. Se, por um instante,

\footnotetext{
18 Ursos de pelúcia dentro dos quais se pode guardar as cinzas de um morto, como urnas alternativas. Esses objetos tornam-se, portanto, "abraçáveis". Disponível em: <http://www.mainelyurns.com/fp-bear-1.html>.
} 
a imagem reinventa o outro e lhe dá um rosto, a seguir ela nos confirma que permanecemos sós.

\section{Referências bibliográficas}

ARIĖS, Philippe. O homem diante da morte. Rio de Janeiro: Francisco Alves, 1981. Vol. 1. 315p.

AUBENAS, Sylvie. Le petit monde de Disdéri. Études photographiques. n. 3, nov. 1997. Disponível em <http://etudesphotographiques.revues.org/93>. Acesso em: 14/10/2013.

AUSTER, Paul. A invenção da solidão. São Paulo: Companhia das Letras, 1999. 194p.

BARTHES, Roland. A câmara clara: nota sobre a fotografia. Rio de Janeiro: Nova Fronteira 1984. $188 \mathrm{p}$.

Diário de Luto: 26 de outubro de 1977 - 15 de setembro de 1979. São Paulo: Martins Fontes, 2011. 256p.

BATCHEN, Geoffrey. Each Wild Idea: writing, photography, history. Londres: The MIT Press, 2000. $236 \mathrm{p}$.

BAUDRY, Patrick. La mémoire des morts. Tumultes. n. 16, p. 29-40, jan. 2001. Disponível em < http:// www.cairn.info/revue-tumultes-2001-1-page-29.htm>. Acesso em: 18/03/2015.

BELTING, Hans. Image, Medium, Body: a new approach to Iconology. Critical Inquiry. Chicago, v. 31, n. 2, p. 302-319, inverno 2005.

BENJAMIN, Walter. Obras escolhidas I. Magia e Técnica, Arte e Política: ensaios sobre literatura e história da cultura. São Paulo: Brasiliense, 1994. 254p.

BLUME, Sandro. Fotografia mortuária: imagens da boa morte. Revista Brasileira de História das Religiões, Maringá, v. V, n. 15, jan. 2013. Disponível em: <http://www.dhi.uem.br/gtreligiao/anais4/ st9/5.pdf>. Acesso em: 06/05/2015.

BORGES, Deborah. A fotografia mortuária no contexto familiar: estudo de retratos produzidos em Bela Vista de Goiás (1920-1960). Domínios da imagem, Londrina, v. 7, n. 13, p. 24-38, jul.-dez. 2013. Disponivel em: <http://www.uel.br/revistas/uel/index.php/dominiosdaimagem/article/view/18557>. Acesso em: 13/03/2017.

CALVINO, Italo. Os amores difíceis. Trad. Raquel Ramalhete. São Paulo: Companhia das Letras, 1992. 258p.

DEBRAY, Régis. Vida e morte da imagem: uma história do olhar no ocidente. Petrópolis: Vozes, 1993. 376p.

GAGNEBIN, Jeanne Marie. Morte da memória, memória da morte: da escrita em Platão. In:

Sete aulas sobre linguagem, memória e história. Rio de Janeiro: Imago, p. 47-65, 2005.

KOURY, Mauro Guilherme Pinheiro. O imaginário urbano sobre fotografia e morte em Belo Horizonte, MG, nos anos finais do século XX. Varia Historia, Belo Horizonte, v. 22, n. 35, p. 100-122, jan.-jun. 2006. Disponível em: <http://www.scielo.br/pdf/rbcsoc/v19n54/a08v1954.pdf>. Acesso em: 06/05/2015.

LINKMAN, Audrey. Photography and Death. Londres: Reaktion Books, 2011. 216p. 
MORCATE, Montse. Duelo y fotografía post-mortem. Contradicciones de una práctica vigente en el siglo XXI. Revista Sans Soleil - Estudios de la Imagen. Barcelona, n. 4, p. 168-181, 2012. Disponível em <http://revista-sanssoleil.com/wp-content/uploads/2012/02/art-Montse-Morcate.pdf>. Acesso em 15/03/2017.

PIETTE, Albert. Détails d'amour ou le lien par l'écriture. Paris: L'Harmattan, 2003. 200p.

$126 \mathrm{p}$. Le temps du deuil: essai d'anthropologie existentielle. Paris: Les Éditions de l'Atelier, 2005.

RIEDL, Titus. Últimas lembranças: retratos da morte no Cariri, região do Nordeste Brasileiro. São Paulo: Annablume; Fortaleza: Secult, 2002. 182p.

RUBY, Jay. Secure the shadow. Death and Photography in America. Cambridge: The MIT Press, 1995. 220p.

SANTOS, Carolina Junqueira dos. Amor, morte, fotografia. Pós: Revista do Programa de PósGraduação em Artes - EBA/UFMG. Belo Horizonte, v. 6, n. 11, maio 2016. Disponível em: <https:// www.eba.ufmg.br/revistapos/index.php/pos/article/view/328/pdf>. Acesso em 24/01/2017.

SOARES, Miguel Augusto Pinto. Representações da morte: fotografia e memória. Dissertação (Mestrado em História). Programa de Pós-Graduação em História da Faculdade de Filosofia e Ciências Humanas, Pontifícia Universidade Católica do Rio Grande do Sul, Porto Alegre, 2007, 148 p.

THOMAS, Louis-Vincent. Rites de mort: pour la paix des vivants. Paris: Fayard, 1985. 294p. La mort en question: traces de mort, mort des traces. Paris: L'Harmattan, 1991. 538p.

VAILATI, Luiz Lima. A morte menina: práticas e representações da morte infantil no Brasil dos oitocentos (Rio de Janeiro e São Paulo). Tese (Doutorado em História Social). Faculdade de Filosofia, Letras e Ciências Humanas, Universidade de São Paulo, São Paulo, 2005. 261p.

Recebido em: 26 de janeiro de 2017.

Aprovado em: 27 de abril de 2017. 